\title{
Studies on the Physicochemical, Functional and Sensory Properties of Gari Processed from Dried Cassava Chips
}

Elohor O Udoro*, Kehinde AT, Olasunkanmi SG and Charles TA

Department of Food Science and Technology, Obafemi Awolowo University, Ile-Ife, Osun State, Nigeria

\begin{abstract}
This study investigated the effects of drying temperature of chips, time of soaking and pressing on the quality of gari processed from dried cassava chips. Fresh cassava tubers were sliced and by sun dried and oven dried at 50 or $70^{\circ} \mathrm{C}$. The chips were processed to gari by milling and soaking in four day old liquor (4DOL) for 3 or 4 days, transferred to the hydraulic press for 3 or 2 days respectively. The mash was sieved, fried, cooled and packaged. The proximate composition, physicochemical and functional properties of the gari samples were determined. Sensory evaluation was carried out on the gari samples in dry granular form and the reconstituted dough form (eba).

The ash (1.54-1.70\%), protein (1.22-1.69\%), crude fibre (2.26-2.49\%) and carbohydrate (82.38-86.48\%) contents of the gari samples were not affected by the processing variables. The $\mathrm{pH}(4.00-6.80)$ of the gari samples decreased with fermentation time. The samples gelled completely at $9 \%(\mathrm{w} / \mathrm{v})$. The pasting temperature $\left(61.53-62.28^{\circ} \mathrm{C}\right)$ of the gari samples were not significantly $(p<0.05)$ different from each other. Solubility $(3.03-38.10 \%)$, swelling capacity $(3.13-8.19)$ and water absorption capacity $(209.06-459.31 \%)$ were significantly $(p>0.05)$ influenced by the drying temperatures of the chips with gari from chips dried at $50^{\circ} \mathrm{C}$ having the highest values. Samples obtained from chips dried at $70^{\circ} \mathrm{C}$, fermented for four days and pressed for two days recorded the highest overall acceptability.
\end{abstract}

Keywords: Dried cassava chips; gari; Physic-chemical properties; Functional properties; Consumer acceptability

\section{Introduction}

Cassava (Manihot esculenta Crantz) belongs to the family Euphorbiaceae. It is a major carbohydrate staple consumed in various forms by humans. It forms a base for a wide variety of fermented foods, in Africa, Asia and Latin America [1,2].

Cassava tubers once harvested begin to deteriorate and cannot be stored for more than a few days. Thus, there is a need for rapid processing of the tubers into a more shelf stable form. Nigeria currently is the largest producer of cassava in the world. Processing the tubers into chips reduced the moisture content to a very low level and reduced postharvest losses $[3,4]$. Cassava can be dried naturally in the sun or artificially in the oven $[5,6]$ to produce dried cassava chips. Chips are commonly used in animal feed production; however several studies have shown that cassava chips can be reconstituted and converted to desired products such as starch, flour [7,8], fufu [6] and gari. Gari is a fermented cassava product and is one of the major products obtained from cassava in the West African sub region [9-11].

Oluwole et al. [12] reported that chips can be converted into gari by seeding (0-20\%) it with fresh root. They reported that almost all the gari samples from the seeded chips gelatinised totally at the same temperature $\left(82.5^{\circ} \mathrm{C}\right)$ with the commercial sample except for the gari sample prepared with unseeded chips. They also reported that gari obtained from dried cassava chips did not swell as much as gari obtained from fresh cassava roots. These they attributed to the treatment the chips received during drying. Taiwo and Okesola [13] reported that the $\mathrm{pH}$ of the mash from dehydrated chips was similar to that processed from fresh cassava in the traditional method, the findings of Oluwole et al. [12] agrees with the afore with the $\mathrm{pH}(4.1-4.5)$ of gari from fresh tubers and those from cassava chips ranging from 4.0 to 4.6 .

Taiwo and Okesola [13] fermented dried chips in 4DOL and reported that gari processed from cassava chips has little or no difference from traditionally processed gari from freshly harvested cassava tubers when considering factors like residual cyanide, texture, moisture content; but taking sensory evaluation into consideration, there was significant difference in colour, flavour and general acceptability. This indicates that the quality of gari from dried cassava chips is yet to be perfected.

This study explored some processing variables that could influence the quality of gari processed from dried cassava chips with a view to establishing the optimum processing condition(s) for production of gari, with optimal functional and sensory characteristics, from dried cassava chips.

\section{Materials and Methods}

Bitter variety (Manihot esculenta Crantz) of freshly harvested cassava tubers (10-12 months old) were purchased from the University Teaching and Research farm on Obafemi Awolowo University Campus, Ile-Ife. All chemicals used were of analytical grade. The method described by FIIRO [5] was used with slight modifications in the production of the chips as shown in Figure 1. The washed cassava tubers were weighed and then manually peeled using a sharp knife after which the weight was taken again. The peeled tubers were diced manually into chips of $2.0 \pm 1.0 \mathrm{~mm}$ thickness using a sharp knife and thickness was measured using a vernier calliper. The diced cassava tubers were divided into three parts. The first part was sun dried by spreading it on perforated steel trays and left in the sun until the diced cassava tubers were dried (average of 3 days). The second and third parts were dried in the oven

*Corresponding author: Elohor O Udoro, Department of Food Science and Technology, Obafemi Awolowo University, Ile-Ife, Osun State, Nigeria, Tel: 234(0)8037922869; E-mail: udoroelohor@yahoo.com

Received July 22, 2013; Accepted January 25, 2014; Published January 31, 2014

Citation: Udoro EO, Kehinde AT, Olasunkanmi SG, Charles TA (2014) Studies on the Physicochemical, Functional and Sensory Properties of Gari Processed from Dried Cassava Chips. J Food Process Technol 5: 293. doi:10.4172/21577110.1000293

Copyright: @ 2014 Udoro EO, et al. This is an open-access article distributed unde the terms of the Creative Commons Attribution License, which permits unrestricted use, distribution, and reproduction in any medium, provided the original author and source are credited. 
500

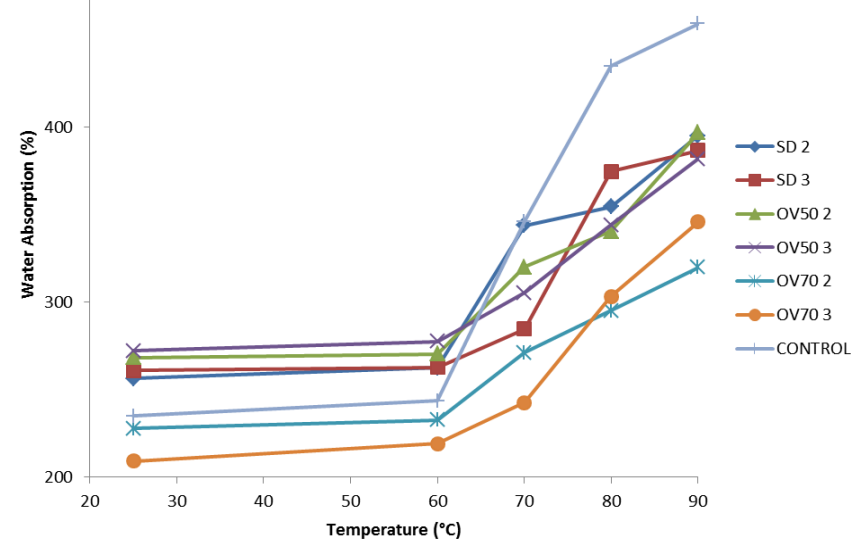

Figure 1: Effect of temperature on water absorption of gari samples.

(DK- 500WT, MRC LTD, Israel) at $50^{\circ} \mathrm{C}$ and $70^{\circ} \mathrm{C}$, respectively for $48 \mathrm{~h}$ to a moisture content of about $10 \pm 2 \%$. The cassava chips obtained were allowed to cool, packed in polythene bags and sealed.

The method described by Irinkoyenikan et al. [6] was employed with slight modifications in preparation of the fermenting medium, four day old liquor (4DOL). Fresh cassava tubers were peeled, washed and cut. $1 \mathrm{~kg}$ of peeled tubers was put into 10 litres of tap water in a bucket, covered and allowed to stand for four days at room temperature. The liquor obtained is known as four day old liquor (4DOL) and was used to initiate fermentation of chips.

The method of Taiwo and Okesola [13] was employed with some modifications in the processing of chips to gari. The samples of dried cassava chips were coarsely milled using a Marlex Excella grinder (Marlex Appliances PVT, Daman) set at speed 1 for $15 \mathrm{sec}$. The coarsely milled chips were divided into two portions. The first portion of all the coarsely milled samples of chips were weighed into a sack (made of muslin cloth) and then immersed in 4-day old liquor (4DOL) for three days at room temperature ( $1 \mathrm{~kg}$ of milled chips in 5 litres of $4 \mathrm{DOL})$ and the sacks were later transferred to a laboratory hydraulic press ( 32 tons) for dewatering (which allowed fermentation to continue for another $48 \mathrm{~h}$ or $72 \mathrm{~h}$ ). The second portion was soaked in a similar manner in $4 \mathrm{DOL}$ for 4 days and pressed for two days. The implication of this was that all the samples were subjected to the same duration of fermentation (6 days) and at room temperature $\left(28 \pm 2^{\circ} \mathrm{C}\right)$. The dough obtained was sieved using a loosely knit sieve (local raffia mat) to disintegrate coarse lumps and remove large particles of cassava tubers in the dough. The semi-dry cassava flour obtained was dried by constant stirring in a heated wrought iron pan until it was dried to about $10 \%$ moisture content. The gari obtained (experimental samples) was cooled, sieved again using the local raffia sieve, and stored in plastic bags. The method of Ene [14] was used to process gari from fresh cassava tubers which served as the control.

\section{Physicochemical and functional Analysis}

The proximate chemical composition of the gari samples was determined using standard AOAC [15] methods.

Water absorption: Capacity of the gari samples was determined by a modification of the method described by Sathe and Salunkhe [16]. Approximately $1 \mathrm{~g}$ of the sample was weighed into a tared $20 \mathrm{ml}$ centrifuge tube and $15 \mathrm{ml}$ of distilled water at different temperatures $\left(60^{\circ} \mathrm{C}-90^{\circ} \mathrm{C}\right)$ added. The mixture was stirred with a glass stirring rod for $60 \mathrm{~s}$ and allowed to stand for $10 \mathrm{~min}$. The suspension was then centrifuged at $3500 \mathrm{~g}$ for $15 \mathrm{~min}$. The supernatant was decanted and the tube allowed to drain at $45^{\circ}$ angle for $10 \mathrm{~min}$ and then weighed. Water absorption was expressed as percentage increase of the sample weight.

Solubility and swelling power: At different temperatures were determined on the gari samples according to a modified version of Sathe and Salunkhe [16] method. The gari samples were milled using attrition mill to pass through a $300 \mu \mathrm{m}$ sieve. Approximately $1 \mathrm{~g}$ of the gari sample was weighed into a previously tared $20 \mathrm{ml}$ centrifuge tube and $15 \mathrm{ml}$ of distilled water was added and stirred for $60 \mathrm{~s}$. The tube was slowly shaken to keep the gari sample agitated and the temperature $\left(60-90^{\circ} \mathrm{C}\right)$ was maintained in a thermostated water bath (Julabo, SW22, Germany) for $30 \mathrm{~min}$. The suspension was then centrifuged (0502-1 Centrifuge, HOSPIBRAND, USA) at $3500 \mathrm{~g}$ for $15 \mathrm{~min}$, the supernatant decanted and the swollen granules were weighed. Swelling power was expressed as the weight of swollen granules (final weight) divided by the sample weight (initial weight). From the supernatant, $5 \mathrm{ml}$ was dried in an air convection oven at $120^{\circ} \mathrm{C}$ for $4 \mathrm{~h}$ in a crucible to constant weight. Solubility was calculated as percentage weight of dry matter in $5 \mathrm{ml}$ of the supernatant after drying according to a modified version of Sathe and Salunkhe [16] method.

Bulk density: Bulk density of the gari samples was determined according to the method of Okezie and Bello [17]. A $10 \mathrm{ml}$ graduated cylinder, was gently filled with the sample, the bottom of the cylinder was gently tapped on a laboratory bench several (about 50) times until there were no further diminution of the sample level after filling to the $10 \mathrm{ml}$ mark. Bulk density was calculated as weight of sample per unit volume of sample $\left(\mathrm{g} / \mathrm{cm}^{3}\right)$.

The method of Sathe and Salunkhe [16] was employed in determining the least gelling concentration of the gari samples. Sample suspensions of $1,3,5,7,9,11,13,15,17$ and $20 \%(\mathrm{w} / \mathrm{v})$ were prepared in $5 \mathrm{ml}$ distilled water and the test tubes were heated in a boiling water bath for $1 \mathrm{~h}$, this was followed by rapid cooling under running cold tap water. The test tubes were further cooled for $2 \mathrm{~h}$ at $4^{\circ} \mathrm{C}$ in a refrigerator. Least gelling concentration was determined as that concentration when the sample from the inverted test tube did not fall down or slip.

Hydrogen cyanide content was determined according to the procedure of Sudarmadji et al. [18] on the gari samples. $10 \mathrm{~g}$ of each sample (ground into flour) was put into a Kjeldahl flask; approximately $200 \mathrm{ml}$ of distilled water was added and allowed to stand for 2-4 h. Thereafter it was steam distilled and about $150-160 \mathrm{ml}$ of the distillate was collected over $2.5 \% \mathrm{NaOH}$ solution. Thereafter $8 \mathrm{ml}$ of $\mathrm{NH}_{4} \mathrm{OH}$ and $2 \mathrm{ml}$ of $5 \% \mathrm{KI}$ were added to $100 \mathrm{ml}$ of the distillate. Finally, the distillate was titrated against $0.02 \mathrm{~N} \mathrm{AgNO}_{3}$. Endpoint was faint but permanent turbidity was easily recognized against a black background.

HCN content was calculated using the equations below:

$$
\begin{aligned}
& H C N(m g)=\frac{m l \text { titrate }(\text { sample }- \text { blank }) * 20 * \text { Normality of } \mathrm{AgNo}_{3} * 0.54}{\text { ml titrate of blank } * 0.02} \\
& H C N \%=\frac{H C N(m g) \times 100 \%}{m g \text { sample }}
\end{aligned}
$$

Particle-size determination: The particle-size distribution of the gari samples was determined according to the method of Ngoddy et al. [19] with slight modifications. $50 \mathrm{~g}$ of gari granules was placed on a tier of sieves (Endecotts LTD, England) arranged in decreasing order of the size of their apertures as follows: $1 \mathrm{~mm}, 630 \mu \mathrm{m}, 500 \mu \mathrm{m}, 425 \mu \mathrm{m}$, $315 \mu \mathrm{m}, 212 \mu \mathrm{m}, 150 \mu \mathrm{m}$ and a collecting base pan. The $1 \mathrm{~mm}$ aperture 
sized sieve was on top and the base pan at the bottom. The sieve was covered with a tight fitted lid and placed on a shaker. The shaker was operated for $10 \mathrm{~min}$ after which gari sample retained on each sieve was weighed. The percentage weight on different sized aperture sieves was calculated as:

$\underline{\text { Weight of sample on sieve } * 100}$ Starting Weight

The average particle size was determined by plotting percentage weight against sieve size on a sieve analysis graph sheet.

The pasting characteristics were determined using a Rapid Visco Analyzer (RVA) (Newport Scientific Pty. Ltd). The RVA was connected to a PC where the pasting properties and curves were recorded directly. Gari suspension was prepared by addition of the equivalent weight of $3.0 \mathrm{~g}$ of gari to $25 \mathrm{ml}$ distilled water to make a total of $28.0 \mathrm{~g}$ suspensions in the RVA sample canister. A paddle was placed inside the canister; this was placed centrally onto the paddle coupling and then inserted into the RVA machine. The measurement cycle was initiated by pressing the motor tower of the instrument. The profile was seen as it was running on the monitor of a computer connected to the instrument. The 12 minute profile of the time-temperature curve of the equipment used was as follows: starting temperature was $50^{\circ} \mathrm{C}$ for $1 \mathrm{~min}$, heated from $50^{\circ} \mathrm{C}$ to $95^{\circ} \mathrm{C}$ for $2 \mathrm{~min} 30 \mathrm{~s}$. The sample was subsequently cooled to $50^{\circ} \mathrm{C}$ for $3 \mathrm{~min} 45 \mathrm{~s}$ period followed by a period of $2 \mathrm{~min}$ where the temperature was controlled at $50^{\circ} \mathrm{C}$. The equivalent sample weight (S) was calculated using the formula:

Sample Weight $=\frac{A * 100}{100-M}$

Where $\mathrm{M}$ is the moisture content of the sample

$\mathrm{A}=$ Initial weight of sample.

Sensory analysis: Sensory analysis was conducted on the gari samples in both the granular meal form and in the reconstituted form (eba). Eba was prepared by adding about $100 \mathrm{~g}$ of gari to $500 \mathrm{ml}$ of hot boiling water and stirred constantly to form a smooth thick paste. Gari and $e b a$ samples were coded and separately subjected to organoleptic evaluation using a 20-man panel (students of the Department of Food Science and Technology, Obafemi Awolowo University, Ile-Ife.) with the aid of questionnaires based on a 7 point hedonic scale (7-like extremely and 1-dislike extremely). The prepared $e b a$ was served with egusi vegetable stew and served in random order. The panelists assessed the coded $e b a$ samples for color, aroma, taste, texture, mouldability and overall acceptability. The coded gari samples (chewed dry) were assessed for colour, aroma, taste, graininess and overall acceptability.

All experiments were conducted in triplicate. Data reported are averages of three determinations. Analysis of variance (ANOVA) was performed and differences in mean values were evaluated using Duncan`s test at $\mathrm{p}<0.05$.

\section{Result and Discussion}

\section{Proximate Composition and Cyanide Content of Gari}

Results of the proximate analysis of gari samples in Table 1 shows that the moisture content of the samples ranged between $7.31 \%$ and $11.04 \%$. The moisture content of food samples is an index of stability and quality and also is a measure of yield and quantity of food solids [20]. The moisture content for gari samples were within the values considered acceptable for dried foods and also within the values reported for gari and other dried samples by earlier workers $[12,13,21,22]$. Ikujenlola et al. [23] reported a value of $11.24 \%$ for gari processed from dehydrated cassava chips. Ash content, which is a measure of the mineral elements, was lowest in the control sample (1.33\%) and highest in gari samples produced from chips dried at $70^{\circ} \mathrm{C}(1.70 \%)$. The protein content of gari samples varied from $1.22 \%-1.69 \%$. The crude fibre of gari samples ranged from $2.26-2.49 \%$ while the carbohydrate contents were within the range $82.38 \pm 1.15 \%$ and $86.48 \pm 3.42 \%$. The analysis of variance showed no significant $(\mathrm{p}<0.05)$ difference in the moisture, ash, crude fibre and carbohydrate content amongst the samples. The results are comparable to the findings of earlier workers Komolafe and Arawande [24] and Ashaye et al. [21]. It can be deduced that the processing variables such as drying temperature for chips, fermentation time as well as dewatering period did not influence the proximate composition of the experimental gari samples which compares favourably with the control [25].

The cyanide content of the gari samples (Table 1) ranged between $0.71 \pm 0.13$ and $1.19 \pm 0.16(\mathrm{mg} / \mathrm{kg})$ which is below the recommended value of $2.0 \mathrm{mg} / \mathrm{kg} \mathrm{HCN}$ for gari and cassava starch [5,3,26,27]. The values obtained in this study are lower than the values $(1.97-2.01$ $\mathrm{mg} / \mathrm{kg}$ ) reported by Taiwo and Okesola [13]. This may be attributed to the difference in fermentation time. It was also observed that the cyanide content decreased with increase in fermentation time. This may be attributed to the prolonged action of micro-organisms (in 4DOL) responsible for fermentation of gari on the chips. Irinkoyenikan et al. [6] reported a decrease in cyanide of chips with increase in fermentation time and attributed this decrease to the breakdown of cyanogenic glucosides in cassava roots during fermentation.

Pressing may also contribute to reduction in cyanide content [28]. The cyanide content of gari processed from dried cassava chips was not significantly different $(\mathrm{P}<0.05)$ from that of gari processed from fresh cassava tubers (control). It can therefore be deduced that dried cassava chips can be used to process gari with safe cyanide content comparable to those from fresh cassava roots. The results also suggest that the various processing methods adequately reduced cyanide content to an acceptable level.

\section{Physicochemical and functional properties of Gari}

The results of Loose Bulk Density (LBD), Packed Bulk Density (PBD), $\mathrm{pH}$, water absorption capacity and solubility of gari samples at room temperature are presented in Table 2. LBD and PBD $\left(\mathrm{g} / \mathrm{cm}^{3}\right)$ ranged from $0.50-0.65\left(\mathrm{~g} / \mathrm{cm}^{3}\right)$ and $0.62-0.78\left(\mathrm{~g} / \mathrm{cm}^{3}\right)$ respectively. Gari processed from fresh cassava tubers had the least packed bulk density value and was significantly ( $\mathrm{p}>0.05)$ different from all the experimental samples. The bulk density either loose or packed is influenced by factors such as dryness and particle size distribution of samples. The values obtained in this study are comparable to that of Komolafe and Arawande [24] who reported the bulk density of gari to be between $0.55-0.82\left(\mathrm{~g} / \mathrm{cm}^{3}\right)$. According to Ukpabi and Ndimele [29] good quality gari should have bulk density of 0.56 to $0.908\left(\mathrm{~g} / \mathrm{cm}^{3}\right)$. High bulk density increases the rate of dispersion which is important in the reconstitution of flours in hot water to produce dough [30]. The bulk density of any product provides vital information on packaging. The processing conditions studied did not influence the PBD or LBD of the samples significantly $(p>0.05)$. The PBD values were higher than those of the LBD but this was not unexpected as the samples were tapped during experimentation to eliminate air spaces during determination of PBD thus resulting in higher values.

The control sample obtained from fresh cassava tubers had the lowest $\mathrm{pH}$ value (4.00) and therefore showed the highest acidity. In 


\begin{tabular}{|c|c|c|c|c|c|c|c|}
\hline Samples & Moisture (\%) & Ash (\%) & Protein (\%) & Crude Fat (\%) & Crude Fibre (\%) & Carbohydrate (\%) & HCN (mg/kg) \\
\hline SD2 & $8.39 \pm 0.57^{\mathrm{ab}}$ & $1.56 \pm 0.10^{\mathrm{b}}$ & $1.52 \pm 0.09^{\mathrm{a}}$ & $1.36 \pm 0.23^{\mathrm{b}}$ & $2.49 \pm 0.31^{\mathrm{a}}$ & $84.61 \pm 1.20^{\mathrm{ab}}$ & $1.14 \pm 0.23^{\mathrm{b}}$ \\
\hline SD3 & $9.74 \pm 0.20^{\mathrm{bc}}$ & $1.54 \pm 0.05^{\mathrm{b}}$ & $1.23 \pm 0.71^{\mathrm{a}}$ & $1.37 \pm 0.64^{\mathrm{b}}$ & $2.43 \pm 0.07^{\mathrm{a}}$ & $83.69 \pm 1.67^{\mathrm{ab}}$ & $0.71 \pm 0.13^{\mathrm{a}}$ \\
\hline OV 50.2 & $7.31 \pm 2.02^{\mathrm{a}}$ & $1.64 \pm 0.03^{\mathrm{b}}$ & $1.22 \pm 0.06^{\mathrm{a}}$ & $1.01 \pm 0.75^{\mathrm{ab}}$ & $2.34 \pm 0.56^{\mathrm{a}}$ & $86.48 \pm 3.42^{\mathrm{b}}$ & $1.18 \pm 0.15^{\mathrm{b}}$ \\
\hline OV50.3 & $11.04 \pm 0.00^{\mathrm{c}}$ & $1.55 \pm 0.13^{\mathrm{b}}$ & $1.63 \pm 0.15^{\mathrm{a}}$ & $1.03 \pm 0.78^{\mathrm{ab}}$ & $2.37 \pm 0.09^{\mathrm{a}}$ & $82.38 \pm 1.15^{\mathrm{a}}$ & $0.82 \pm 0.11^{\mathrm{ab}}$ \\
\hline OV70.2 & $9.24 \pm 0.61^{\mathrm{b}}$ & $1.70 \pm 0.21^{\mathrm{b}}$ & $1.31 \pm 0.48^{\mathrm{a}}$ & $0.34 \pm 0.02^{\mathrm{a}}$ & $2.26 \pm 0.17^{\mathrm{a}}$ & $85.15 \pm 1.49^{\mathrm{ab}}$ & $1.19 \pm 0.16^{\mathrm{b}}$ \\
\hline OV70.3 & $9.35 \pm 0.28^{\mathrm{b}}$ & $1.70 \pm 0.14^{\mathrm{b}}$ & $1.69 \pm 0.26^{\mathrm{a}}$ & $0.53 \pm 0.04^{\mathrm{ab}}$ & $2.45 \pm 0.52^{\mathrm{a}}$ & $84.28 \pm 1.24^{\mathrm{ab}}$ & $1.02 \pm 0.18^{\mathrm{ab}}$ \\
\hline Control & $9.05 \pm 0.14^{\mathrm{b}}$ & $1.33 \pm 0.02^{\mathrm{a}}$ & $1.61 \pm 1.21^{\mathrm{a}}$ & $1.40 \pm 0.10^{\mathrm{b}}$ & $2.47 \pm 0.82^{\mathrm{a}}$ & $84.14 \pm 1.29^{\mathrm{ab}}$ & $1.06 \pm 0.04^{\mathrm{ab}}$ \\
\hline
\end{tabular}

SD2, Sun dried chips (soaked three days and pressed three days)

SD3, Sun dried chips (soaked four days and pressed two days)

OV 502 , Oven dried chips at $50^{\circ} \mathrm{C}$ (soaked three days and pressed three days)

OV 503 , Oven dried chips at $50^{\circ} \mathrm{C}$ (soaked four days and pressed two days)

OV 702 , Oven dried chips at $70^{\circ} \mathrm{C}$ (soaked three days and pressed three days)

OV 703 , Oven dried chips at $70^{\circ} \mathrm{C}$ (soaked four days and pressed two days)

Control, Processed from fresh cassava tubers

Value with similar letters in the same column are not significantly $(p<0.05)$ different.

Table 1: Proximate composition and Cyanide content of gari samples.

\begin{tabular}{|c|c|c|c|c|c|}
\hline Sample & WAC (\%) & $\operatorname{LBD}\left(\mathbf{g} / \mathrm{cm}^{3}\right)$ & PBD $\left(\mathrm{g} / \mathrm{cm}^{3}\right)$ & $\mathrm{pH}$ & Solubility (\%) \\
\hline SD2 & $256.32 \pm 13.62^{\mathrm{bc}}$ & $0.60 \pm 0.01^{b}$ & $0.71 \pm 0.01^{\mathrm{b}}$ & $6.80 \pm 0.07^{f}$ & $0.26 \pm 0.06^{\mathrm{ab}}$ \\
\hline SD3 & $261.00 \pm 9.90^{\mathrm{bc}}$ & $0.61 \pm 0.02^{b}$ & $0.74 \pm 0.01^{e}$ & $4.03 \pm 0.00^{b}$ & $0.30 \pm 0.05^{\mathrm{abc}}$ \\
\hline OV50 2 & $268.41 \pm 0.31^{c}$ & $0.65 \pm 0.01^{c}$ & $0.78 \pm 0.01^{f}$ & $4.80 \pm 0.00^{d}$ & $0.11 \pm 0.09^{a}$ \\
\hline OV50 3 & $272.08 \pm 8.86^{c}$ & $0.61 \pm 0.02^{b}$ & $0.72 \pm 0.02^{c d}$ & $4.55 \pm 0.07^{c}$ & $0.22 \pm 0.03^{\mathrm{ab}}$ \\
\hline OV70 2 & $227.71 \pm 3.43^{\mathrm{a}}$ & $0.61 \pm 0.01^{b}$ & $0.73 \pm 0.01^{\mathrm{de}}$ & $5.95 \pm 0.07^{e}$ & $0.44 \pm 0.03^{\text {bc }}$ \\
\hline OV70 3 & $209.06 \pm 7.71^{\mathrm{a}}$ & $0.60 \pm 0.02^{b}$ & $0.71 \pm 0.00^{\mathrm{bc}}$ & $4.10 \pm 0.00^{\mathrm{a}}$ & $0.46 \pm 0.03^{b c}$ \\
\hline Control & $234.96 \pm 32.88^{a b}$ & $0.50 \pm 0.01^{a}$ & $0.62 \pm 0.01^{a}$ & $4.00 \pm 0.00^{a}$ & $0.54 \pm 0.12^{c}$ \\
\hline
\end{tabular}

SD 2, Sun dried chips (soaked three days and pressed three days)

SD 3, Sun dried chips (soaked four days and pressed two days)

OV 502 , Oven dried chips at $50^{\circ} \mathrm{C}$ (soaked three days and pressed three days)

OV 503 , Oven dried chips at $50^{\circ} \mathrm{C}$ (soaked four days and pressed two days)

OV 702 , Oven dried chips at $70^{\circ} \mathrm{C}$ (soaked three days and pressed three days)

OV 703 , Oven dried chips at $70^{\circ} \mathrm{C}$ (soaked four days and pressed two days)

Control, Processed from fresh cassava tubers

LBD, Loose bulk density

PBD, Packed bulk density

WAC, Water absorption capacity at room temperature

Values with similar letters within the same column are not significantly $(p<0.05)$ different.

Table 2: Physicochemical and functional properties of gari.

experimental samples, $\mathrm{pH}$ values varied from 4.03-6.80 with gari processed from sun dried chips, soaked for three days and pressed for three $\left(\mathrm{SD}_{2}\right)$ having the highest $\mathrm{pH}$ of 6.8 (almost neutral). All the experimental samples showed a sharp drop in $\mathrm{pH}$ with increase in soaking time. Samples soaked for 4 days and pressed for 2 days had lower $\mathrm{pH}$ values compared to those soaked for 3 days and pressed for 3 days. This may be due to increased production of lactic and other organic acids due to enhanced activities of lactic acid bacteria responsible for fermentation of cassava in the fermenting medium. This is in agreement with the findings of Irinkoyenikan et al. [6] that the $\mathrm{pH}$ of cassava roots decreased with increase in steeping time. There was significant difference $(\mathrm{p}<0.05)$ in the $\mathrm{pH}$ values of the samples but no discernible consistent trend was observed in this difference as a result of the processing conditions.

The solubility of gari samples at room temperature as shown in Table 2 varied between $0.11 \pm 0.09 \%$ and $0.54 \pm 0.12 \%$. Generally there was no significant difference in the solubility of all the experimental samples at room temperature. Solubility reflects the extent of intermolecular cross bonding between granules [31]. This indicates that the drying temperature of chips had no significant effect on the solubility of the gari samples at room temperature. There was significant difference $(p<0.05)$ in the solubility values of the samples but no discernible consistent trend was observed in this difference as a result of the processing conditions.

The water absorption capacity of the gari samples at room temperature varied between 234.96 - 272.08\% with samples from chips dried in the oven at $50^{\circ} \mathrm{C}$ having the highest values. That of the control sample was not significantly $(\mathrm{p}<0.05)$ different from the water absorption capacities of gari processed from sun dried and $70^{\circ} \mathrm{C}$ oven dried chips. This result indicates that gari from chips will absorb water adequately for soaking (drinking gari) as well as gari from fresh tubers. The water absorption capacity of chips oven dried at $70^{\circ} \mathrm{C}$ were lower ( $p>0.05)$ than the values for the other processed chips. The values obtained in this study are within the range $(215-445 \%)$ reported by Arawande and Komolafe [24].

The water absorption of gari samples as influenced by temperature is shown in Figure 1. The gari samples from different processing conditions exhibited water absorption capacities ranging from 219.92 to $459.31 \%$. Water absorption capacity is the ability of a flour to absorb water and swell for improved consistency in food. It is desirable in food systems to improve yield, consistency and give body to the food [32]. The water absorption capacity increased with increase in temperature. Oluwole et al. [12] explained that at elevated temperatures, the molecules are subjected to random movement causing the intermolecular and intramolecular forces to be broken and the material in question will imbibe greater volume of water. The gari samples processed from $70^{\circ} \mathrm{C}$ oven dried chips exhibited the least water absorption capacity at all of the temperatures (60-90C) studied. This could be attributed to the possible pre gelatinization or denaturation of the starch content of fresh cassava tubers during oven drying at $70^{\circ} \mathrm{C}$ to dried chips. This 
suggests that the temperature at which chips are dried influences the water absorption capacity of gari processed from them. Gari processed from fresh cassava tubers (control) exhibited distinctly higher (435.15$459.31 \%$ ) water absorption capacity at temperatures above $70^{\circ} \mathrm{C}$. Ruales et al. [33] reported that the water retention capacity of a starch granule indicates the degree of exposure of the internal structure of the starch granules to water. The values obtained in this study are comparable to the results (256-388\%) of Ankrah [34] for gari samples in Accra. He attributed the range of values to the difference in starch levels of cassava tubers. The swelling pattern of a flour suggest the level of crystalline packing of the starch granules present in the flour [35]. The results in this study showed that the processing of gari from dried cassava chips had a declining effect on the water absorption capacity at temperatures above $70^{\circ} \mathrm{C}$. The time of soaking and pressing during fermentation did not influence the water absorption capacity of the samples.

The influence of temperature on the percentage solubility of gari samples is presented in Figure 2. The solubility of the samples ranged between $3.03-38.10 \%$ at temperatures of $60-90^{\circ} \mathrm{C}$. Increase in temperature resulted in increase in solubility for all the samples. According to Hoover and Maunal [36] an increase in temperature facilitated the hydrolysis of starch leading to an improved solubility.

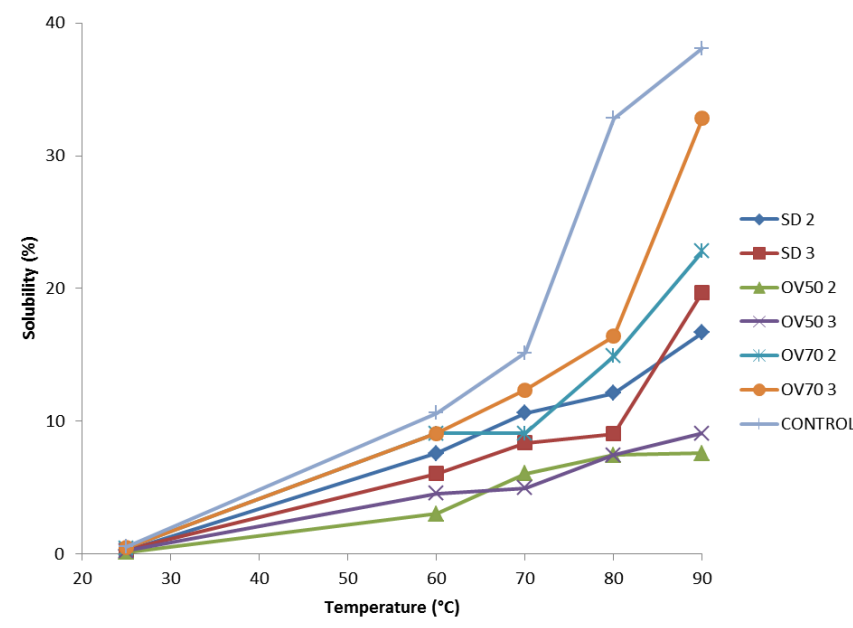

Figure 2: Effect of temperature on solubility of gari.

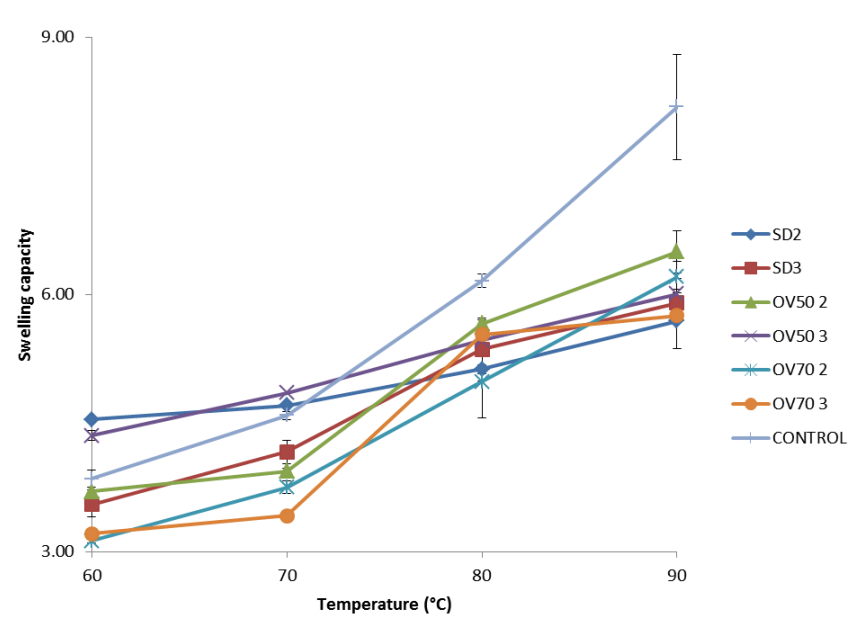

Figure 3: Effect of temperature on swelling capacity of gari.
Solubility increased as the temperature increased because of increase in mobility of the starch granules which facilitated enhanced dispersion of starch molecules in water [37]. Water molecules readily penetrated the intermolecular spaces of carbohydrates resulting in enhanced solubility [38]. It was observed that the control sample exhibited the highest (10.61-38.10\%) solubility at all the temperatures investigated. Sample OV70.3 (oven dried at $70^{\circ} \mathrm{C}$, soaked for four days and pressed for two days) exhibited solubility values (9.09-32.80\%) close to the control while gari samples from chips dried in the oven at $50^{\circ} \mathrm{C}$ had the least percentage solubility. The effect of fermentation time or pressing time was not consistent.

The swelling capacity as a function of temperature shown in Figure 3 varied between 3.13 and 8.19. Gari samples processed from oven dried chips at $70^{\circ} \mathrm{C}$, fermented by soaking in $4 \mathrm{DOL}$ for three days and pressed for three days (OV70.2) exhibited the lowest (3.13-5.3) swelling capacity while gari processed from fresh cassava tubers (control) had the highest (4.8 - 8.19) swelling capacity. However, at lower temperatures $\left(60-70^{\circ} \mathrm{C}\right)$, the gari samples exhibited low swelling capacities when compared to the high temperatures of $80-90^{\circ} \mathrm{C}$ where the samples swelled more than five times their initial dry weight. It was also observed that the swelling capacity of the control sample was significantly $(\mathrm{p}>0.05)$ higher than all other samples at temperatures above $70^{\circ} \mathrm{C}$. Gari samples from chips dried at $50^{\circ} \mathrm{C}$ exhibited water absorption and swelling capacities closest to the control. It therefore suggests that the drying temperature of fresh cassava tubers to chips had a reducing effect on the swelling capacity of gari produced from the chips at higher temperatures $\left(80-90^{\circ} \mathrm{C}\right)$ when compared to gari from fresh tubers. Swelling capacity, the ability of gari particles to absorb water and swell, depends on the free amylose and associative forces within the starch granules and moisture content [39]. As temperature increases, the starch granules imbibe water and swell. Further increase in temperature caused amylose molecules to leach out from the granules into the cooking water which increased the viscosity and therefore resulted in decreased swelling capacity. The findings in this study partly agree with that of Oluwole et al. [12] that at temperatures of $80-90^{\circ} \mathrm{C}$, gari obtained from dried cassava chips did not swell as much as gari obtained from fresh cassava roots but that at lower temperatures $\left(60-70^{\circ} \mathrm{C}\right)$ the gari obtained from dried cassava chips swelled as much as that obtained from fresh cassava. This means gari from chips will swell adequately for soaking (drinking gari) but may not give as good a volume when used to make $e b a$ when compared to gari from fresh tubers. This was attributed to the treatment of chips during drying which may have resulted in the general weakening of the starch structure thus, lowering swelling capabilities. However the values obtained in this study are similar to those of Achinewu et al. [40], IITA [2], Achinewu et al. [39], Udofia et al. [22] and according to the IITA [2], good quality gari may swell to about three times its initial volume when placed in water.

The gelling concentration of the gari samples is presented in Table 3 . All the experimental gari samples were fully gelled at $9 \%(w / v)$ and the control gelled fully at $11 \%(\mathrm{w} / \mathrm{v})$. Gelling of the experimental samples occurred at a lower concentration than that of the control. It therefore implies that the variation in the processing (drying temperature) of gari from dried cassava chips had no effect on the gelling ability of the gari samples. Gelation is an important functional property of food materials which affects its texture. The gelatinization process is a property of the starch granule found in cereals and tuber crops. The least gelling concentration indicates the amount of gari per volume of water that will be required to prepare the gelatinized form ' $e b a$ '. These results show that less quantity of the gari samples processed from dried chips will be required to prepare a stable gel when compared to gari samples produced 


\begin{tabular}{|c|c|c|c|c|c|c|c|}
\hline Percentage (w/v) & SD2 & SD3 & OV50.2 & OV50.3 & OV70.2 & OV70.3 & Control \\
\hline 1 & - & - & - & - & - & - & - \\
\hline 3 & - & - & - & - & - & - & - \\
\hline 5 & - & - & - & - & - & - & - \\
\hline 7 & - & \pm & \pm & \pm & \pm & \pm & - \\
\hline 9 & + & + & + & + & + & + & \pm \\
\hline 11 & + & + & + & + & + & + & + \\
\hline 13 & + & + & + & + & + & + & + \\
\hline 15 & + & + & + & + & + & + & + \\
\hline 17 & + & + & + & + & + & + & + \\
\hline 19 & + & + & + & + & + & + & + \\
\hline
\end{tabular}

SD2, Sun dried chips (soaked three days and pressed three days)

SD3, Sun dried chips (soaked four days and pressed two days)

OV50.2, Oven dried chips at $50^{\circ} \mathrm{C}$ (soaked three days and pressed three days)

OV50.3, Oven dried chips at $50^{\circ} \mathrm{C}$ (soaked four days and pressed two days)

OV70.2, Oven dried chips at $70^{\circ} \mathrm{C}$ (soaked three days and pressed three days)

OV70.3, Oven dried chips at $70^{\circ} \mathrm{C}$ (soaked four days and pressed two days)

Control, Processed from fresh cassava tubers

- Not gelled

\pm Partially gelled

+ Completely gelled

Table 3: Gellation of gari samples.

\begin{tabular}{|c|c|c|c|c|c|c|c|}
\hline Property & SD2 & SD3 & OV50.2 & OV50.3 & OV70.2 & OV70.3 & Control \\
\hline $\mathrm{PV}(\mathrm{cP})$ & $93.67 \pm 0.47^{b}$ & $163.38 \pm 4.42^{\mathrm{d}}$ & $193.58 \pm 3.54^{\mathrm{e}}$ & $147.25 \pm 4.24^{c}$ & $88.92 \pm 1.59^{a}$ & $95.50 \pm 2.23^{b}$ & $145.92 \pm 0.83^{c}$ \\
\hline TV (cP) & $89.67 \pm 0.23^{b}$ & $158.79 \pm 4.65^{d}$ & $177.42 \pm 0.23^{e}$ & $141.33 \pm 4.83^{c}$ & $70.50 \pm 3.78^{a}$ & $93.17 \pm 1.53^{b}$ & $138.38 \pm 4.18^{c}$ \\
\hline $\mathrm{BV}(\mathrm{cP})$ & $4.00 \pm 0.71^{\mathrm{ab}}$ & $4.59 \pm 0.23^{\mathrm{ab}}$ & $16.17 \pm 3.77^{c}$ & $5.92 \pm 0.59^{a b}$ & $18.42 \pm 2.18^{c}$ & $2.33 \pm 0.71^{a}$ & $7.55 \pm 3.36^{\mathrm{ab}}$ \\
\hline $\mathrm{FV}(\mathrm{cP})$ & $164.42 \pm 0.23^{b}$ & $245.21 \pm 9.49^{d}$ & $275.12 \pm 2.65^{e}$ & $219.29 \pm 7.13^{a}$ & $90.04 \pm 7.13^{a}$ & $152.17 \pm 1.65^{b}$ & $214.83 \pm 2.00^{c}$ \\
\hline $\mathrm{SV}(\mathrm{cP})$ & $74.75 \pm 0.00^{\mathrm{b}}$ & $86.42 \pm 4.83^{c}$ & $97.71 \pm 2.89^{d}$ & $77.96 \pm 2.53^{b}$ & $54.80 \pm 3.36^{a}$ & $59.00 \pm 0.11^{\mathrm{a}}$ & $76.46 \pm 6.19^{b}$ \\
\hline $\mathbf{P}_{\text {Temp }}\left({ }^{\circ} \mathrm{C}\right)$ & $61.68 \pm 0.18^{a}$ & $62.08 \pm 0.35^{a}$ & $61.70 \pm 0.14^{a}$ & $61.53 \pm 0.11^{a}$ & $62.10 \pm 0.00^{a}$ & $61.68 \pm 0.11^{a}$ & $62.28 \pm 0.88^{a}$ \\
\hline
\end{tabular}

SD.2, Sun dried chips (soaked three days and pressed three days)

SD.3, Sun dried chips (soaked four days and pressed two days)

OV 50.2, Oven dried chips at $50^{\circ} \mathrm{C}$ (soaked three days and pressed three days);

OV 50.3 , Oven dried chips at $50^{\circ} \mathrm{C}$ (soaked four days and pressed two days)

OV 70.2 , Oven dried chips at $70^{\circ} \mathrm{C}$ (soaked three days and pressed three days)

OV 70.3 , Oven dried chips at $70^{\circ} \mathrm{C}$ (soaked four days and pressed two days)

Control, Processed from fresh cassava tubers

PV, Peak viscosity

TV, trough viscosity

$\mathrm{BV}$, breakdown viscosity

FV, final viscosity

SV, setback viscosity

PTemp, pasting temperature

Values with different letters in the same row are significantly $(p<0.05)$ different

Table 4: Pasting properties of gari processed from dried cassava chips

from fresh tubers. This implies that the pre-processing conditions did not significantly adversely $(\mathrm{p}<0.05)$ alter the starch structure which means that good $e b a$ can be made from the experimental samples.

The pasting properties of the gari samples from different processing conditions are presented in Table 4 . The pasting temperature which provides an indication of the minimum temperature required to reconstitute (in hot water) a given sample and also indicate energy costs ranged from $61.53-62.28^{\circ} \mathrm{C}$. It is characterized by an initial change in the viscosity due to the swelling properties of the starch granules. Pasting temperature, which is a reflection of the swelling of the starch granules, is affected by the starch concentration. The gelatinization temperatures are usually characteristic of a particular starch and usually lie between $55-70^{\circ} \mathrm{C}$ [41]. There was no significant difference $(\mathrm{p}<0.05)$ in the pasting temperature of all the gari samples. This implies that the processing variables such as the drying temperatures of chips, the soaking and pressing time (fermentation) had no significant effect $(p<0.05)$ on the amount of energy that would be required to cook any of the gari samples.

The particle size distribution of gari samples processed from dried cassava chips under varying conditions and fresh cassava tubers is shown in Table 5 . The percentage weight of particles retained on $1 \mathrm{~mm}$ aperture sieve ranged between 24.82 and $57.17 \%$. All of the experimental samples except gari processed from sun dried chips, soaked for 3 days and pressed for 3 days $\left(\mathrm{SD}_{2}\right)$ and the control sample had about $70-80 \%$ of their particles retained on $625 \mu \mathrm{m}-1 \mathrm{~mm}$ sieves and this could be attributed to the crushing of chips before fermenting in $4 \mathrm{DOL}$. There was no significant difference $(\mathrm{p}<0.05)$ in the weight of samples retained on $425-630 \mu \mathrm{m}$ sieves. The control exhibited values significantly $(\mathrm{p}<0.05)$ different from all the experimental samples in all the investigated sieve ranges. The difference in particle size exhibited by the samples suggests that the different processing procedures such as the grating of fresh tubers to mash before fermentation had significant ( $p>0.05)$ effect on the particle size distribution of gari samples processed from it. The range of particle size in foods depends on the cell structure and the degree of processing [42]. On the basis of the particle size distribution and average particle size, the control sample could be described as having moderately fine texture. The particle size of foods in dry granular form such as gari influences sensory attributes 
Citation: Udoro EO, Kehinde AT, Olasunkanmi SG, Charles TA (2014) Studies on the Physicochemical, Functional and Sensory Properties of Gari Processed from Dried Cassava Chips. J Food Process Technol 5: 293. doi:10.4172/2157-7110.1000293

Page 7 of 8

\begin{tabular}{|c|c|c|c|c|c|c|c|}
\hline Aperture size & SD2 & SD3 & OV50.2 & OV50.3 & OV70.2 & OV70.3 & Control \\
\hline $1 \mathrm{~mm}$ & $57.17 \pm 4.58^{e}$ & $34.29 \pm 0.43^{b}$ & $32.17 \pm 0.42^{b}$ & $40.00 \pm 0.64^{\mathrm{cd}}$ & $38.65 \pm 0.76^{c}$ & $42.57 \pm 0.71^{d}$ & $24.82 \pm 0.57^{a}$ \\
\hline $425-630 \mu \mathrm{m}$ & $36.90 \pm 1.02^{b}$ & $34.81 \pm 0.89^{a}$ & $38.67 \pm 0.76^{a b}$ & $41.05 \pm 0.30^{\mathrm{ab}}$ & $42.62 \pm 0.40^{\mathrm{ab}}$ & $38.36 \pm 0.25^{\mathrm{ab}}$ & $60.65 \pm 0.97^{c}$ \\
\hline $150-315 \mu \mathrm{m}$ & $5.95 \pm 0.78^{a}$ & $30.83 \pm 1.26^{\mathrm{e}}$ & $29.18 \pm 0.33^{d}$ & $18.98 \pm 0.39^{c}$ & $18.76 \pm 0.21^{c}$ & $19.07 \pm 0.40^{c}$ & $14.56 \pm 0.15^{\mathrm{b}}$ \\
\hline APS $\mu \mathrm{m}$ & $662.50 \pm 3.54^{d}$ & $514.00 \pm 5.66^{a}$ & $525.00 \pm 7.07^{a}$ & $585.00 \pm 7.07^{c}$ & $567.50 \pm 10.61^{c}$ & $575.00 \pm 7.07^{c}$ & $535.00 \pm 7.07^{b}$ \\
\hline
\end{tabular}

SD2, Sun dried chips (soaked three days and pressed three days)

SD3, Sun dried chips (soaked four days and pressed two days)

OV50.2, Oven dried chips at $50^{\circ} \mathrm{C}$ (soaked three days and pressed three days)

OV50.3, Oven dried chips at $50^{\circ} \mathrm{C}$ (soaked four days and pressed two days)

OV70 2, Oven dried chips at $70^{\circ} \mathrm{C}$ (soaked three days and pressed three days)

OV70.3, Oven dried chips at $70^{\circ} \mathrm{C}$ (soaked four days and pressed two days)

Control, Processed from fresh cassava tubers

APS, Average particle size

Values with similar letters in the same column are not significantly $(p<0.05)$ different.

${ }^{*}$ Starting weight $=50 \mathrm{~g}$

Table 5: Percentage weight on different size apertures and average particle size of gari.

\begin{tabular}{|c|c|c|c|c|c|c|c|}
\hline $\begin{array}{l}\text { Quality } \\
\text { Attributes }\end{array}$ & SD2 & SD3 & OV50.2 & OV50.3 & OV70.2 & OV70.3 & Control \\
\hline Color & $1.40 \pm 0.50^{a}$ & $2.60 \pm 1.10^{\mathrm{b}}$ & $3.90 \pm 1.48^{c}$ & $3.45 \pm 1.05^{c}$ & $4.60 \pm 1.39^{d}$ & $5.30 \pm 0.98^{e}$ & $6.85 \pm 0.37^{f}$ \\
\hline Aroma & $2.35 \pm 1.34^{a}$ & $2.30 \pm 0.98^{\mathrm{a}}$ & $3.75 \pm 1.21^{b}$ & $3.80 \pm 1.11^{\mathrm{b}}$ & $3.60 \pm 1.47^{b}$ & $3.80 \pm 1.24^{b}$ & $6.60 \pm 0.50^{c}$ \\
\hline Taste & $2.40 \pm 1.19^{a}$ & $2.65 \pm 1.04^{\mathrm{a}}$ & $3.50 \pm 1.24^{b c}$ & $3.05 \pm 1.05^{\mathrm{ab}}$ & $3.55 \pm 1.54^{b c}$ & $3.90 \pm 1.33^{c}$ & $6.45 \pm 0.69^{d}$ \\
\hline Graininess & $2.50 \pm 1.10^{a}$ & $2.95 \pm 1.32^{\mathrm{ab}}$ & $3.85 \pm 1.46^{\mathrm{cd}}$ & $3.45 \pm 1.36^{\mathrm{bc}}$ & $4.25 \pm 1.71^{\mathrm{cd}}$ & $4.35 \pm 1.46^{d}$ & $6.50 \pm 0.51^{e}$ \\
\hline $\begin{array}{c}\text { Overall } \\
\text { Acceptability }\end{array}$ & $2.05 \pm 0.94^{\mathrm{a}}$ & $2.65 \pm 1.04^{\mathrm{a}}$ & $3.85 \pm 1.18^{b}$ & $3.70 \pm 0.80^{\mathrm{b}}$ & $4.35 \pm 1.14^{b}$ & $4.25 \pm 1.07^{b}$ & $6.70 \pm 0.47^{c}$ \\
\hline
\end{tabular}

SD2, Sun dried chips (soaked three days and pressed three days)

SD3, Sun dried chips (soaked four days and pressed two days)

OV50.2, Oven dried chips at $50^{\circ} \mathrm{C}$ (soaked three days and pressed three days)

OV 50.3, Oven dried chips at $50^{\circ} \mathrm{C}$ (soaked four days and pressed two days)

OV70.2, Oven dried chips at $70^{\circ} \mathrm{C}$ (soaked three days and pressed three days)

OV70.3, Oven dried chips at $70^{\circ} \mathrm{C}$ (soaked four days and pressed two days)

Table 6: Sensory evaluation of gari processed from dried cassava chips.

\begin{tabular}{|c|c|c|c|c|c|c|c|}
\hline $\begin{array}{c}\text { Quality } \\
\text { Attributes }\end{array}$ & SD2 & SD3 & OV50.2 & OV50.3 & OV70.2 & OV70.3 & Control \\
\hline Color & $1.10 \pm 0.45^{\mathrm{a}}$ & $3.65 \pm 1.42^{b}$ & $3.95 \pm 1.28^{b}$ & $3.75 \pm 1.65^{b}$ & $5.20 \pm 1.11^{c}$ & $5.15 \pm 1.46^{c}$ & $6.80 \pm 0.41^{d}$ \\
\hline Aroma & $1.75 \pm 0.72^{\mathrm{a}}$ & $3.00 \pm 0.79^{b}$ & $3.75 \pm 1.25^{\mathrm{cd}}$ & $3.50 \pm 0.24^{b c}$ & $4.25 \pm 1.41^{d}$ & $4.40 \pm 1.05^{d}$ & $6.55 \pm 0.69^{e}$ \\
\hline Taste & $1.95 \pm 1.10^{a}$ & $2.75 \pm 0.97^{a}$ & $3.40 \pm 1.54^{b c}$ & $3.50 \pm 1.15^{b c}$ & $3.75 \pm 1.59^{c}$ & $3.85 \pm 1.63^{c}$ & $6.55 \pm 0.69^{d}$ \\
\hline Texture & $3.10 \pm 1.41^{a}$ & $3.75 \pm 1.16^{\mathrm{ab}}$ & $4.15 \pm 1.14^{b}$ & $4.20 \pm 1.36^{b}$ & $4.25 \pm 1.45^{b}$ & $4.20 \pm 1.32^{b}$ & $6.50 \pm 0.76^{c}$ \\
\hline Mouldability & $3.90 \pm 1.80^{\mathrm{a}}$ & $4.45 \pm 1.36^{\mathrm{ab}}$ & $4.40 \pm 1.43^{\mathrm{ab}}$ & $4.45 \pm 1.10^{\mathrm{ab}}$ & $4.00 \pm 1.65^{\mathrm{ab}}$ & $4.95 \pm 1.36^{b}$ & $6.60 \pm 0.68^{c}$ \\
\hline $\begin{array}{c}\text { Overall } \\
\text { acceptability }\end{array}$ & $2.25 \pm 1.21^{\mathrm{a}}$ & $3.65 \pm 0.93^{b}$ & $4.20 \pm 0.95^{\mathrm{bcd}}$ & $3.90 \pm 0.97^{b c}$ & $4.55 \pm 1.15^{\mathrm{cd}}$ & $4.85 \pm 1.14^{\mathrm{d}}$ & $6.60 \pm 0.68^{e}$ \\
\hline
\end{tabular}

SD2, Sun dried chips (soaked three days and pressed three days)

SD3, Sun dried chips (soaked four days and pressed two days)

OV50.2, Oven dried chips at $50^{\circ} \mathrm{C}$ (soaked three days and pressed three days)

OV50.3, Oven dried chips at $50^{\circ} \mathrm{C}$ (soaked four days and pressed two days)

OV70.2, Oven dried chips at $70^{\circ} \mathrm{C}$ (soaked three days and pressed three days)

OV70.3, Oven dried chips at $70^{\circ} \mathrm{C}$ (soaked four days and pressed two days)

Control, Processed from fresh cassava tubers

Value with similar letters in the same column are not significantly $(p<0.05)$ different.

Table 7: Sensory evaluation of gari (in form of eba) processed from dried cassava chips.

such as graininess, mouth feel, texture and consistency of the food when consumed dry, soaked or in dough form.

Results of sensory evaluation in their dry granular form and reconstituted dough form (eba) are shown in Tables 6 and 7 respectively. The results on both evaluations followed a similar trend, the overall acceptability increased with increase in fermentation time, the samples from sun dried chips had the least scores this could be attributed to their dark colour, followed by samples from chips dried in the oven at $50^{\circ} \mathrm{C}$, the control had the highest scores which was followed by samples processed from chips dried in the oven at $70^{\circ} \mathrm{C}$ with about $70 \%$ overall acceptability. Colour - on a 7 point hedonic scale, sundried samples obtained less than average scores but those oven dried had greater than average scores (i.e. above 3.5) and better scores were obtained on samples dried at $70^{\circ} \mathrm{C}$. This trend was observed for all the characteristics tested- graininess, aroma, taste and overall acceptability. Above average scores for colour is an improvement compared to earlier results published by Taiwo et al. [13] and Oluwole et al. [12]. These studies reported poor colours for gari samples from dried chips.

\section{Summary and Conclusion}

The cyanide content, proximate composition, pasting temperature and water absorption at room temperature of gari processed from dried cassava chips compared favourably with gari from fresh tubers. The result of water absorption at room temperature indicates that gari from chips will absorb water adequately for soaking (drinking gari) as well as gari from fresh tubers

The physicochemical, functional and sensory properties of the 
Citation: Udoro EO, Kehinde AT, Olasunkanmi SG, Charles TA (2014) Studies on the Physicochemical, Functional and Sensory Properties of Gari Processed from Dried Cassava Chips. J Food Process Technol 5: 293. doi:10.4172/2157-7110.1000293

experimental samples were greatly influenced by the processing variables. Gari samples from dried chips gelled at a lower concentration than the control. The results on both sensory evaluations followed a similar trend, the overall acceptability increased with increase in soaking time. Gari from oven dried chips had better sensory attributes $\left(70^{\circ} \mathrm{C}\right.$ was most preferred) than gari from sun dried chips (appeared dark).

Conclusively, this study shows that gari with relatively good physicochemical, functional and sensory characteristics (which compares favourably with gari from fresh cassava tubers) could be processed from dried cassava chips.

\section{Acknowledgement}

The authors are grateful to Obafemi Awolowo University Research Committee for funding the research through project No: 11812AMX.

The first author acknowledges the Carnegie Corporation, New York, for a cash scholarship received in the course of this work.

\section{References}

1. Aloys N, Ming ZH (2006) Traditional cassava food in Burundi. Food Rev Int 22: 1-27.

2. Taiwo KA (2006) Utilization Potentials of Cassava in Nigeria: The Domestic and Industrial Products. Food Rev Int 22: 29-42.

3. IITA (1990) Cassava in Tropical Africa: A Reference Manual, International Institute of Tropical Agriculture.

4. Ugwu WO (1996) Cassava cultivation in West Africa. Outlook on Agriculture 18: $72-81$.

5. Federal Institute of Industrial Research (2005) Cassava processing. FIIRO Oshodi, Lagos, Nigeria.

6. Irinkoyenikan OA, Taiwo KA, Gbadamosi SO, Akanbi C T (2008) Studies of fufu Production From Cassava Chips, Proceedings of Humboldt - Kolleg Held A The Obafemi Awolowo University, lle-lfe, Nigeria, sponsored by Alexander von Humboldt Foundation, Germany.

7. Famokunwa OE (1994) Production of dehydrated cassava chips for starch and flour (fufu). Unpublished B.Sc. Thesis in Food Science and Technology. Obafemi Awolowo University, Ile-Ife, Nigeria.

8. Olomo V, Ajibola $\mathrm{O}$ (2006) Processing factors affecting the yield and physiochemical properties of starch from cassava chips and flour. StarchStarke 55: 476-481.

9. Eggleston G, Bokanga M, Jean YW (1992) Traditional African methods for cassava processing and utilisation and research needs. Proceedings 4th Triennial Symposium, International Society for Tropical Root Crops- Africa Branch, Kinshasa Zaire.

10. Onabolu AO, Oluwole OSA, Rosling H, Bokanga M (2002) Processing factors affecting the levels of residual cyanohydrins in gari. J Sci Food Agri 82: 966969.

11. Nago CM (1995) Artisanal gari production in Benin. Technological and and physico-chemical aspects. Cassava processing. Paris ORSTOM editions.

12. Oluwole OB, Olatunji OO, Odunfa SA (2004) A process technology for conversion of dried cassava chips into gari. Nigerian Food Journal 22: 65-77.

13. Taiwo KA, Okesola CO (2009) A study of some processing factors on the production of gari (A fermented product) from dehydrated Cassava Chips. AICHE.

14. Ene LSO (1992) Prospects for processing and utilisation of root and tube crops in Africa. Proceedings 4th Triennial Symposium, International Society for Tropical Root Crops- Africa Branch.

15. AOAC (1990) Association of Official Analytical Chemists. Official methods of Analysis. 13th edition. Washington DC, USA

16. Sathe SK, Salunkhe DK (1981) Isolation, partial characterization and modification of Great Northern Bean (Phaseolus vulgaris L.) starch. J Food Sci 46: 617-621.

17. Okezie BO, Bello AB (1988) Physicochemical and functional properties of winged bean flour and isolate compared with soy isolate. J Food Sc 53: 450454
18. Sudarmadji SB (1984) Prosedur analisa untuk bahan makanen and pertanian Edisi Ketiga: Liberty. Yogyakarta: 138

19. Ngoddy PO, Enwere NJ, Onuorah VI (1986) Cowpea flour performance in akara and moin-moin preparations. Trop Sci 26: 101-119.

20. Joslyn MA (1970) Methods in Food Analysis, 2nd Edition. Academic Press, London. pp 67.

21. Ashaye OA, Couple AA, Fasoyiro SB, Adeniji AM (2005) Effect of location and Storage Environment on the Quality Attributes of gari in South-West Nigeria World J Agri Sci 1: 52-55.

22. Udofia PG, Udoudo PJ, Eyen NO, Udoekong NS (2010) Optimizing gari quality attributes for different groups of consumers with response surface methodology. J Agri Biotechnol Sustain Develop 3: 28-34.

23. Ikunjelola AV, Omosuli SV (2009) Dehydrated Cassava Chips Utilisation in Starch and "Garri” Production. Adv Mat Res 62-64: 203-207.

24. Komolafe EA, Arawande JO (2010) Evaluation of the quantity and quality of gari produced from three cultivars of cassava. Journal of Research in National Development 8.

25. IITA (1989) Lowering Cyanide Levels in Cassava. International Institute of Tropical Agriculture. Research Briefs 9: 1-3.

26. Standard Organization of Nigeria (1983) Nigeria industrial standard for gari. SON Lagos, Nigeria.

27. Standard Organization of Nigeria (2004) Nigeria industrial standard for gari. SON Lagos, Nigeria.

28. Blanshard AFJ, Dahniya MT, Poulter NH, Taylor AJ (1994) Fermentation of cassava into foofoo: Effect of time and temperature on pressing and storage quality. J Sci Food Agri 66: 485-492.

29. Ukpabi UJ, Ndimele C (1990) Evaluation of the quality of gari produced in Imo State. Nigeria Food Journal 8: 105-109.

30. Brennan JG, Butters JR, Cowell ND, Lielly AEV (1976) Effect of agglomeration on the properties of spray-dried roaibos tea. Int J Food Sci Technol 23: 43-48.

31. Numfor FA, Walter WM Jr, Schwartz SJ (1995) Physicochemical changes in cassava starch and flour associated with fermentation; Effect on textural properties. Starch-Starke 47: 86-89.

32. Osundahunsi OF, Fagbemi TN, Kesselman E, Shimoni E (2003) Comparison of the physicochemical properties and pasting characteristics of flour and starch from red and white sweet potato cultivars. J Agri Food Chem 51: 2232-2236.

33. Ruales J, Valencia S, Nair B (1993) Effect of processing on physico-chemical properties of quinon flour (chenopodium quinon). Starch 45: 13-19.

34. Ankrah EK (2000) Quality evaluation of samples of gari from Ghana. Ghana J Agric Sci 33: 111-113.

35. Muhammad AS, Haq N, Mazhar H, Beena $Y$ (2011) Proximate composition and functional properties of rhizomes of lotus (Nelumbo Nucifera) from Punjab Pakistan. Pak J Bot 43: 895-904.

36. Hoover R, Maunal H (1996) Effect of heat moisture treatment on the structure and physicochemical properties of legumes starches. Food Res Int 29: 731 750

37. Adebowale AA, Sanni LO, Awonorin SO (2005) Effect of texture modifiers on the physicochemical and sensory properties of dried fufu. Food Sci Technol Int 11: 373-382.

38. Hwang J, Kokini JL (1991) Structure and rheological function of side branches of carbohydrate polymers. J Textural Study 22: 123-167.

39. Achinewu SC, Barber LI, ljeoma IO (1998) Physicochemical Properties and Gari yield of some selected cassava cultivars in Rivers State, Nigeria. Plant Foods for Human Nutrition 52: 133-140.

40. Achinewu SC (1990) Toxic components of food and their mode of removal. Public lecture Rivers State University of Science and Technology, Port Harcourt

41. Coultate TP (1989) Food the Chemistry of its Components. Burlington House Piccadilly, London.

42. Sahin S, Sumnu SG (2006) Physical Properties of Food. Springer Science, New York, USA. 